\title{
PENGARUH KEPEMIMPINAN DAN LINGKUNGAN KERJA TERHADAP KEPUASAN KERJA DENGAN STRES KERJA SEBAGAI VARIABEL INTERVENING PADA PT WASTEFORCHANGE ALAM INDONESIA
}

\begin{tabular}{lcl}
\multicolumn{3}{c}{$\begin{array}{c}\text { Hendri Jopanda } \\
\text { Universitas Satya Negara Indonesia } \\
\text { humas@ } @ \text { usni.ac.id }\end{array}$} \\
\hline Received : & Accepted : & Published: \\
1 Januari 2022 & 15 Februari 2022 & 25 Februari 2022 \\
\hline
\end{tabular}

\section{ABSTRAK}

Sumber daya manusia merupakan salah satu kunci keberhasilan suatu organisasi. Hal ini karena sumber daya manusia yang membuat perusahaan berjalan sebagaimana mestinya. Kinerja karyawan yang baik akan mendorong tujuan organisasi, dan salah salah satu pendorongnya yaitu tingkat kepuasan kerja karyawan itu sendiri. Banyak hal yang dapat memengaruhi kepuasan kerja, beberapa diantaranya yaitu kepemimpinan, lingkungan kerja, dan stres kerja. Penelitian ini bertujuan untuk mengetahui serta menganalisis pengaruh kepemimpinan dan lingkungan kerja terhadap kepuasan kerja dengan stres kerja sebagai variabel intervening. Sampel yang digunakan dalam penilitian ini adalah seluruh karyawan pada PT Wasteforchange Alam Indonesia. Metode yang digunakan dalam penelitian yaitu Analisis Jalur dengan software SPSS 2.4 sebagai sarana untuk pengolahan data. Hasil penelitian menunjukkan bahwa kepemimpinan berpengaruh positif secara signifikan terhadap kepuasan kerja karyawan, lingkungan kerja berpengaruh positif secara signifikan terhadap kepuasan kerja karyawan, dan stres kerja berpengaruh negatif secara signifikan terhadap kepuasan kerja karyawan. Kepemimpinan berpengaruh negatif secara signifikan terhadap stres kerja dan lingkungan kerja berpengaruh negatif secara signifikan terhadap stres kerja. Kepemimpinan berpengaruh secara langsung terhadap kepuasan kerja tanpa melalui stres kerja, dan lingkungan kerja berpengaruh secara langsung terhadap kepuasan kerja tanpa melalui stres kerja.

\section{Kata kunci : Kepuasan kerja, kepemimpinan, lingkungan kerja, stres kerja}

\section{ABSTRACT}

Human resources is one of the keys to the success of an organization, this is because human resources makes company work properly. Good employee performance will support the achievement of organizational goals and one of the triggers is the level of employee job satisfaction. Many factors can affect job satisfaction, some of them are leadership, work environment, and job stress. This research aims to find out and analyze the effect of leadership and work environment on job satisfaction with job stress as an intervening variable. The sample used in this research is all employees at PT Wasteforchange Alam Indonesia. The method used in this research is Path Analysis with SPSS 2.4 software as a tool for data processing. The results showed that leadership had a significant positive effect on employee job satisfaction, work environment has significant positive effect on employee job satisfaction, and job stress has significant negative effect on job satisfaction. Leadership has significant negative effect on work stress and work environment has significant negative effect on work stress. Leadership has a direct effect on employee job satisfaction without going through work stress, and work environment has a direct effect on employee job satisfaction without going through work stress.

\section{Keywords: Job satisfaction, leadership, work environment, job stress}




\section{PENDAHULUAN}

Dalam menghadapi era globalisasi, setiap perusahaan berlomba untuk dapat bersaing dan menjadi yang terbaik dalam mencapai target bisnisnya. Faktor penting yang menunjang keberlangsungan serta kemajuan suatu perusahaan adalah Sumber Daya Manusia (SDM). SDM juga merupakan kunci yang menentukan perkembangan perusahaan. Hal ini juga diungkapkan oleh Arni Anti Kinas (2018) yang mengatakan bahwa Sumber Daya Manusia adalah aset bagi perusahaan yang mempunyai fungsi penting dalam menunjang tujuan perusahaan karena sumber daya manusia merupakan penggerak segala aktivitas yang terjadi dalam suatu perusahaan. Bagus atau tidaknya kualitas suatu perusahaan ditentukan oleh kualitas sumber daya manusia. Maka dari itu, penting sekali bagi suatu perusahaan berusaha untuk meningkatkan kepuasan kerja bagi karyawannya untuk menunjang kinerjanya.

Kepuasan kerja akan mendorong kinerja karyawannya, hal ini juga dikemukakan oleh Tjiong Fei Lie dan Hotlan Siagian (2018) dalam penelitiannya mengenai pengaruh kepuasan kerja terhadap kinerja karyawan melalui motivasi kerja. Hasil penelitian tersebut menunjukkan bahwa kepuasan kerja berpengaruh positif dan signifikan terhadap kinerja karyawan, dengan demikian semakin tinggi tingkat kepuasan karyawan, maka kinerja akan semakin meningkat.

Kepuasan kerja merupakan bagian yang sangat penting dan menarik karena terbukti sangat penting manfaatnya. Kepuasan kerja adalah sikap yang positif dari tenaga kerja meliputi perasaan dan tingkah laku terhadap pekerjaannya melalui penilaian salah satu pekerjaan sebagai rasa menghargai dalam mencapai salah satu nilai-nilai penting pekerjaan (Afandi, 2018 : 74). Kepuasan kerja karyawan mempunyai beberapa faktor yang dapat mempengaruhi, salah satu faktor yang mempengaruhi kepuasan karyawan adalah Kepemimpinan.

Kepuasan kerja akan mendorong kinerja karyawannya, hal ini juga dikemuka- kan oleh Tjiong Fei Lie dan Hotlan Siagian (2018) dalam penelitiannya mengenai pengaruh kepuasan kerja terhadap kinerja karyawan melalui motivasi kerja. Hasil penelitian tersebut menunjukkan bahwa kepuasan kerja berpengaruh positif dan signifikan terhadap kinerja karyawan, dengan demikian semakin tinggi tingkat kepuasan karyawan, maka kinerja akan semakin meningkat.

Kepemimpinan adalah cara pemimpin ketika mempengaruhi perilaku bawahan agar mereka mau bekerja sama dan bekerja secara produktif untuk mencapai tujuan organisasi (Malayu S.P Hasibuan, 2016:170). Gaya kepemimpinaan adalah bagaimana cara atau gaya seorang pemimpin bertindak untuk mempengaruhi anggotanya untuk mencapai tujuan yang telah ditetapkan (Dr. Emron Edison, 2016:93). Kepemimpinan menjadi faktor pertama dalam meningkatkan kepuasan kerja secara berkelanjutan. Pada proses ini pemimpin mempunyai peran yang besar dalam menentukan pelaksanaan organisasi suatu perusahaan. Seorang pemimpin dituntut untuk mampu memberikan arahan yang jelas terhadap visi dan misi organisasi tersebut, dan mampu menjalankan organisasi dengan baik agar hasil yang didapatkan sesuai dengan tujuan yang ingin dicapai oleh perusahaan. Selain dari faktor kepemimpinan yang dapat mendorong kepuasan kerja, faktor lain adalah lingkungan kerja karyawan.

Lingkungan kerja dapat mendorong seorang karyawan dalam melaksanakan pekerjaan secara maksimal sesuai dengan tujuan yang diinginkan oleh seorang pemimpin dalam menciptakan suasana kerja yang kondusif dalam perusahaan. Lingkungan kerja menurut Afandi (2018:66) adalah sesuatu yang ada dilingkungan para pekerja yang dapat mempengaruhi dirinya dalam menjalankan pekerjaannya seperti suhu, humiditas, aliran udara, penerangan, kegaduhan, kebersihan tempat kerja, dan memadai tidaknya alat perlengkapan kerja. Lingkungan kerja dapat diartikan sebagai keseluruhan alat perkakas yang dihadapi, lingkungan sekitarnya dimana seorang pekerja, metode kerjanya, sebagai pengaruh kerjanya baik sebagai perorangan maupun sebagai kelompok. 
Selain faktor Kepemimpinan dan lingkungan kerja, faktor lain yang berpengaruh terhadap kepuasan kerja adalah stres kerja karyawan. Hasibuan (2017:204) mendefinisikan stres kerja merupakan suatu kondisi ketegangan yang mempengaruhi emosi, proses berpikir, dan kondisi seseorang. Banyak faktor yang mempengaruhi stres kerja, baik faktor internal maupun faktor eksternal. Stres kerja dapat terjadi karena timbulnya tekanan dan tuntutan berlebih yang dibebankan kepada seorang pekerja, sehingga dapat memengaruhi munculnya ketegangan seseorang dalam bekerja. Stres kerja yang tinggi dapat menurunkan kepuasan kerja, dan begitu juga sebaliknya. Pengelolaan sampah Indonesia merupakan salah satu penggerak perekonomian yang memiliki peranan penting dalam perkembangan ekonomi bangsa. PT Wasteforchange Alam Indonesia merupakan salah satu perusahaan yang bergerak pada bidang pengolahan sampah di Indonesia yang perkembangannya cukup pesat di era globalisasi saat ini. PT Wasteforchange sedang berusaha meningkatkan kinerja karyawannya dalam rangka pencapaian tujuan perusahaan secara optimal. Perusahaan yang juga kerap dikenal dengan Waste4Change ini melakukan banyak hal untuk meningkatkan kinerja karyawannya, dan salah satunya adalah meningkatkan kepuasan kerja karyawan. Hal ini dibuktikan dengan diadakannya survey kepuasan kerja pada tahun 2020 serta survey stres kerja atau burnout pada karyawannya.

Hasil survey kepuasan kerja menunjukkan bahwa linkungan kerja memiliki tingkat kepuasan paling rendah dibandingkan dengan indikator lainnya, yaitu sebanyak 11\% dari total karyawan merasakan tidak puas dan sebanyak 13\% netral dalam hal lingkungan kerja. Pada tahun 2021, penulis melakukan pra survey mengenai kepemimpinan dan menunjukkan bahwa Pra-survey dilakukan kepada 30 karyawan PT Wasteforchange Alam Indonesia. Hasil pra-survey dalam dimensi Hubungan dengan dan menunjukkan bahwa sebanyak 7\% karyawan setuju bahwa pimpinan memiliki hubungan yang kurang baik dan sebanyak 52\% pimpinan kurang mempertimbangkan kondisi/ situasi karyawan dalam pengambilan keputusan. Pada dimensi Struktur Tugas memperlihatkan bahwa sebanyak 59\% karyawan setuju bahwa pimpinan kurang jelas dalam mendelegasikan tugas, dan sebanyak $52 \%$ setuju bahwa pimpinan memberikan pekerjaan dengan prosedur yang kurang jelas. Pada dimensi Kekuatan Posisi, menunjukkan bahwa sebanyak $74 \%$ karyawan setuju bahwa pimpinan kurang tegas dalam memberikan sanksi/ hukuman, dan sebanyak 48\% setuju bahwa pimpinan tidak selalu atau jarang melakukan evaluasi kinerja karyawan. Hasil survey menunjukkan sebanyak 60,9\% karyawan memiliki tingkat tingkat 3 pada level stres yang artinya pada level hati - hati karena sudah terdeteksi gejala burnout, sebanyak $9,8 \%$ pada level 4 yang artinya waspada terhadap gejala burnout, dan sebanyak 2,2\% level 5 yang artinya sudah level tinggi pada gejala burnout dan harus ditindaklanjut untuk mengelola burnout yang dialami. Adapun indikator yang digunakan pada survey ini, yaitu beban pekerjaan, lingkungan kerja, dan gejala stres kerja. Maka dari itu, penulis ingin meneliti lebih lanjut mengenai fenomena ini burnout/ stres kerja.

Berdasarkan fenomena masalah dalam latar belakang penelitian ini dan masih terdapatnya perbedaan hasil penelitian sebelumnya, maka peneliti mengambil penelitian ini dengan judul: Pengaruh Kepemimpinan dan Lingkungan Kerja Terhadap Kepuasan Kerja Karyawan dengan Stres Kerja sebagai Variabel Intervening Pada Pt Wasteforchange Alam Indonesia.

\section{METODE PENELITIAN}

Penelitian ini menggunakan metode penelitian kuantitatif. Dalam penelitian ini menggunakan data primer, yaitu data yang bersumber dari responden yang bersedia mengisi kuesioner. Kuesioner yang digunakan terdiri dari pertanyaan yang dibentuk secara struktural dan dikualifikasikan dengan skala likert. Data responden yang telah terkumpul akan dilakukan 
pengolahan data dengan menghitung tiap jawaban pernyataan dari tiap responden tentang variabel dalam penelitian, yaitu kepemimpinan, lingkungan kerja, stres kerja serta kepuasan kerja.

\section{POPULASI}

Sasaran populasi yang digunakan dalam penelitian ini adalah karyawan pada PT Wasteforchange Alam Indonesia.

\section{SAMPEL}

Metode sampel jenuh adalah teknik penentuan sampel bila semua anggota populasi digunakan menjadi sampel. Dalam penelitian ini sebanyak 90 karyawan atau sama dengan $100 \%$ populasi.

\section{HASIL}

Tabel 4.9

Hasil Regresi Struktur I

\begin{tabular}{|l|c|r|r|r|}
\hline Model & R & R Square & Adjusted R Square & Std. Error of the Estimate \\
\hline 1 & $.500^{\mathrm{a}}$ & .250 & .232 & 9.504 \\
\hline
\end{tabular}
a. Predictors: (Constant), X1, X2

Berdasarkan tabel diatas diperoleh hasil perhitungan R Square (R2) sebesar 0,250. Hal ini menunjukan bahwa besarnya kontribusi variabel kepemimpinan dan lingkungan kerja terhadap stres kerja sebesar $25 \%$ sisanya dipengaruhi oleh variabel lain yang tidak diteliti dalam penelitian ini. Dari hasil dari pengolahan data di atas, didapatkan nilai e1 dengan rumus : e1 = $\sqrt{ }(1-0,250)=0,866$.

Setelah mendapatkan e1, selanjutnya dapat dilakukan pencarian nilai signifikansi pada variabel stres kerja sebagai variabel dependen, sedangkan variabel kepemimpinan dan lingkungan kerja sebagai variabel independent.

Tabel 4.10

\section{Output Uji Analisis Jalur}

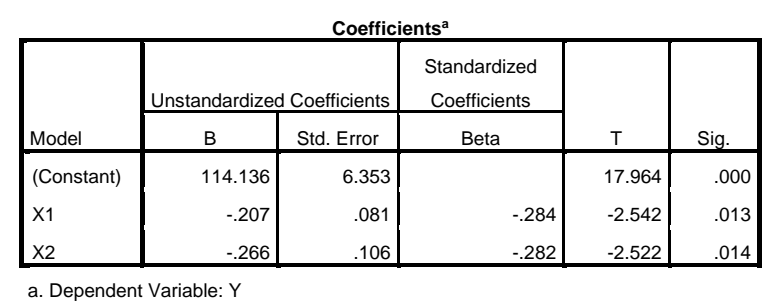

Signifikansi pada variabel kepemimpinan terhadap stres kerja senilai 0,013 dan pada lingkungan kerja senilai 0,014. Kedua variabel ini memiliki nilai lebih kecil daripada 0,05, maka dapat ditarik kesimpulan bahwa regresi struktur I yang dapat digambarkan sebagai berikut : 


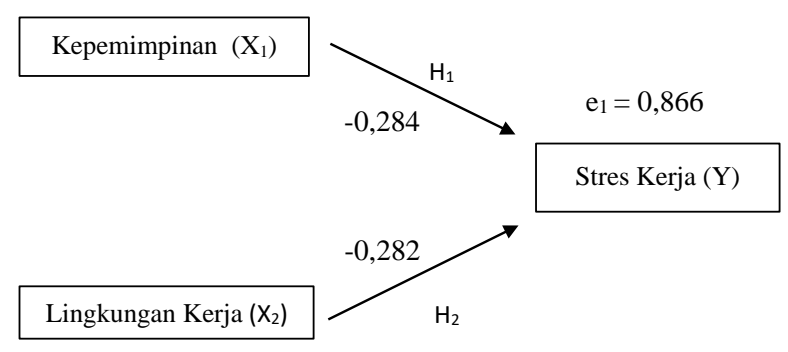

Gambar 4.7 Jalur Sub Struktur I

\section{Analisis Jalur Sub Struktur 1I}

Hasil pengolahan data regresi struktur II yaitu sebagai berikut :

Tabel 4.11

\section{Hasil Regresi Struktur II}

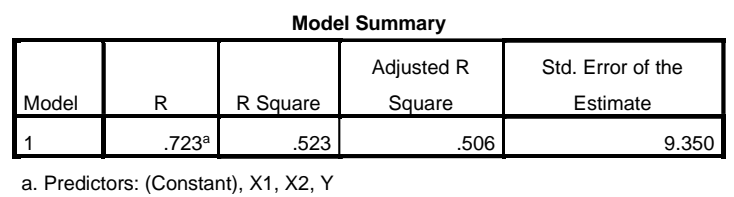

Berdasarkan tabel diatas diperoleh hasil perhitungan $R$ Square $\left(\mathrm{R}^{2}\right)$ sebesar 0,523. Hal ini menunjukan bahwa besarnya kontribusi variabel kepemimpinan, lingkungan kerja dan stres kerja terhadap kepuasan kerja sebesar 52,3\% sisanya dipengaruhi oleh variabel lain yang tidak diteliti dalam penelitian ini.

Besarnya R Square terdapat pada tabel Model Summary dalam hasil pengujian koefisian determinasi terhadap variabel stres kerja adalah sebesar 0,250. Nilai e2 dapat dicari dengan rumus e2 $=\sqrt{ }(1-0,523)=0,6906$. Setelah mendapatkan nilai e2, dilakukan uji analisis jalur, dan mendapatkan hasil berikut :

Tabel 4.12

Output Analisis Jalur

\begin{tabular}{|c|c|c|c|c|c|}
\hline \multirow[b]{2}{*}{ Model } & \multicolumn{2}{|c|}{ Unstandardized Coefficients } & \multirow{2}{*}{$\begin{array}{c}\text { Standardized } \\
\text { Coefficients } \\
\text { Beta } \\
\end{array}$} & \multirow[b]{2}{*}{$t$} & \multirow[b]{2}{*}{ Sig. } \\
\hline & $\mathrm{B}$ & Std. Error & & & \\
\hline (Constant) & 64.161 & 13.564 & & 4.730 & .000 \\
\hline $\mathrm{X} 1$ & .207 & .083 & .232 & 2.496 & .014 \\
\hline $\mathrm{x} 2$ & .435 & .108 & .375 & 4.042 & .000 \\
\hline $\mathrm{Y}$ & -.347 & .105 & -.283 & -3.287 & .001 \\
\hline
\end{tabular}

Variabel kepemimpinan terhadap kepuasan kerja memiliki nilai signifikansi sebesar 0,014. Nilai signifikan pada variabel lingkungan kerja sebesar 0,000. Pada variabel stres kerja terhadap kepuasan kerja memiliki nilai signifikan sebesar 0,001. Hasil pengujian memperlihatkan nilai signifikan dari ketiga variabel independen terhadap variabel kepuasan kerja sebagai variabel dependen, lebih kecil dari 0,05. Hal tersebut menunjukkan bahwa 
regresi struktur II memiliki pengaruh terhadap kepuasan kerja. Dari hasil pengujian yang dilakukan juga, nilai beta dan dapat digambarkan diagram jalur struktur II sebagai berikut :

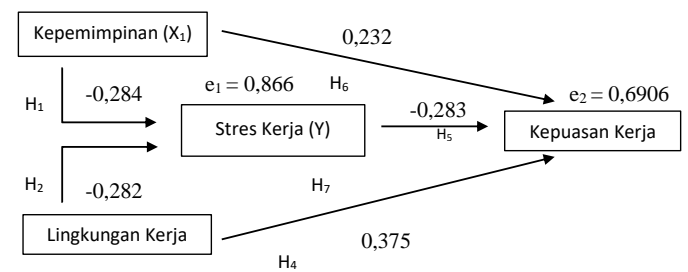

Sumber : Diolah oleh Penulis Gambar 4.9 Jalur Sub Struktur II

\section{PEMBAHASAN}

Berdasarkan hasil dari pengujian hipotesis yang telah dirangkum pada tabel diatas, maka dapat diuraikan secara singkat sebagai berikut ini :

A. Pengaruh Kepemimpinan ( $\mathrm{X}_{1)}$ Terhadap Stres Kerja (Y)

Variabel X1 terhadap Y diketahui dengan nilai signifikan sebesar 0,013<0,05. Sehingga dapat disimpulkan bahwa secara langsung terdapat pengaruh antara Kepemimpinan terhadap Stres Kerja.

B. Pengaruh Lingkungan (X2) Terhadap Stres Kerja (Y)

Variabel X2 terhadap Y diketahui dengan nilai signifikan sebesar 0,014 $<0,05$. Sehingga dapat disimpulkan bahwa secara langsung terdapat pengaruh antara Lingkungan Kerja terhadap Stres Kerja.

C. Pengaruh Kepemimpinan (X1) Terhadap Kepuasan Kerja (Z)

Variabel X1 terhadap Z diketahui dengan nilai signifikan sebesar sig 0,014 < 0,05. Sehingga dapat disimpulkan bahwa secara langsung terdapat pengaruh antara Kepemimpinan terhadap Kepuasan Kerja.

D. Pengaruh Lingkungan Kerja (X2) Terhadap Kepuasan Kerja (Z)

Variabel X2 terhadap Z diketahui dengan nilai signifikan sebesar 0,000 $<0,05$. Sehingga dapat disimpulkan bahwa secara langsung terdapat pengaruh antara Lingkungan Kerja terhadap Kepuasan Kerja.

E. Pengaruh Stres Kerja (Y) Terhadap Kepuasan Kerja (Z)

Variabel Y terhadap Z diketahui dengan nilai signifikan sebesar $0,000<0,00$. Sehingga dapat disimpulkan bahwa secara langsung terdapat pengaruh antara Stres Kerja terhadap Kepuasan Kerja.

F. Pengaruh Kepemimpinan (X1) Terhadap Kepuasan Kerja (Z) Melalui Stres Kerja (Y)

Hasil dapat diketahui pengaruh langsung $X 1$ terhadap $Z$ sebesar 0,232, sedangkan pengaruh tidak langsung X1 terhadap $\mathrm{Z}$ melalui $\mathrm{Y}$ sebesar 0,08 , maka pengaruh langsung sebesar 0,232 dan pengaruh tidak langsung sebesar 0,08 yang artinya perngaruh tidak langsung lebih kecil dari pengaruh langsung. Hal ini menunjukkan bahwa kepemimpinan berpengaruh secara langsung terhadap kepuasan kerja.

G. Pengaruh Lingkungan Kerja (X2) Terhadap Kepuasan Kerja (Z) Melalui Stres Kerja (Y) Hasil dapat diketahui pengaruh langsung. X1 terhadap Z sebesar 0,375, sedangkan pengaruh tidak langsung X2 terhadap Z melalui Y sebesar 0,079 maka pengaruh langsung sebesar 0,375 dan pengaruh tidak langsung sebesar 0,079 yang artinya perngaruh tidak langsung lebih 
kecil dari pengaruh langsung. Hal ini menunjukkan bahwa kepemimpinan berpengaruh secara langsung terhadap kepuasan kerja.

\section{KESIMPULAN}

Dari pembahasan sebelumnya, maka dapat ditarik kesimpulan dari penelitian sebagai berikut :

A. Kepemimpinan berpengaruh negatif secara signifikan terhadap stres kerja pada karyawan PT Wasteforchange Alam Indonesia.

B. Lingkungan kerja berpengaruh negatif signifikan terhadap stres kerja pada karyawan PT Wasteforchange Alam Indonesia.

C. Kepemimpinan berpengaruh positif secara signifikan terhadap kepuasan kerja pada karyawan PT Wasteforchange Alam Indonesia.

D. Lingkungan kerja berpengaruh negatif signifikan terhadap kepuasan kerja pada karyawan PT Wasteforchange Alam Indonesia.

E. Stres kerja berpengaruh negatif dan signifikan terhadap kepuasan kerja pada karyawan PT Wasteforchange Alam Indonesia.

F. Lingkungan kerja berpengaruh positif dan langsung secara signifikan terhadap kepuasan kerja, tanpa melalui stres kerja sebagai variabel intervening, pada karyawan PT Wasteforchange Alam Indonesia.

G. Kepemimpinan berpengaruh positif dan langsung secara signifikan terhadap kepuasan kerja, tanpa melalui stres kerja sebagai variabel intervening, pada karyawan PT Wasteforchange Alam Indonesia.

\section{DAFTAR PUSTAKA}

AA. Anwar Prabu Mangkunegara. 2017. Manajemen Sumber Daya Manusia Perusahaan. Bandung : Rosda.

Afandi, Pandi. 2018. Manajemen Sumber Daya Manusia;Teori, konsep dan. Indiktor. Yogyakarta : Zanafa Publishing.

Asih, Gusti Yuli, Hardani Widhiastuti, Rusmalia Dewi. 2018. Stress Kerja. Semarang : Semarang University Press.

Enny, Mahmudah. 2019. Manajemen Sumber Daya Manusia. Surabaya : Ubhara Manajemen Press.

Bahri, Moh Saiful. 2018. Pengaruh Kepemimpinan, Lingkungan Kerja, Budaya Organisasi dan Motovasi terhadap Kepuasan Kerja yang berimplikasi terhadap Kinerja Dosen. Surabaya : Jakad Publishing.

Hasibuan, Malayu S.P. 2016. Manajemen Sumber Daya Manusia. Edisi. Revisi. Jakarta: Penerbit PT Bumi Aksara.

Sedarmayanti. (2017). Manajemen Sumber Daya Manusia. Bandung: Refika Aditama.

Sudaryo, Aribowo, Sofiati. 2018. Manajemen Sumber Daya Manusia (Kompensasi Tidak Langsung Dan Lingkungan Kerja Fisik). Yogyakarta: Penerbit Andi.

Sugiyono. 2017. Metode Penelitian Kuantitatif, kualitatif dan R\&D. Bandung: Alfabeta.

Sugiyono. 2018. Metode Penelitian Kuantitatif, kualitatif dan R\&D. Bandung: Alfabeta. 
Sutrisno, Edy. 2017. Manajemen Sumber Daya Manusia. Jakarta: Kencana.

Tawel Bernhard Tewal, Adolfina, Merinda Ch. H. Pandowo, Hendra N. Tawas. 2017. Perilaku Organisasi. Bandung: Patra Media Grafindo.

Wibowo. 2016. Manajemen Perubahan. Jakarta: Rajawali Pers

\section{Jurnal}

Aoliso1, Adveni dan Hans Lao. 2018. Pengaruh Lingkungan Kerja Terhadap Kepuasan Kerja Karyawan pada PT Taspen (Persero) Kantor Cabang Kupang Bisman. Jurnal Bisnis \& Manajemen Vol 3 No. 1.

Arni Anti Kinas. 2018. Analisis Pengembangan Sumber Daya Manusia (Studi Kasus pada Perusahaan Swasta di Kota Makasar). Jurnal Ilmiah Pena Vol.1 Nomor 2 Tahun.

Azis, A. 2019. Pengaruh Fasilitas, Kemampuan, dan Disiplin Kerja Terhadap Kinerja Pegawai Kantor Kecamatan Tinombo Kabupaten Parigi Moutong. Jurnal Ekonomi Trend, 7(2).

David dan Sri Nova Sari. 2017. Influence of Work Dicipline, Job Stress, Non Physical Work Environment Through Employee Job Satisfaction at Oxy Family Reflexy and Facial Pekanbaru. Jurnal Pelita Indonesia Vol. 5 No. 4.

Friatma, A., Syamsurizal, S., \& Helendra, H. 2017. Analyzed Quality Question of Final Exam Whole Semester on Biology Course Class XI IPA SMA Negeri District South of Solok Selatan Academic Year 2015/2016. Bioeducation Journal, 1(2), 50-67 Jakarta: Rineka Cipta.

Habibi, A. A. (2019). Pengaruh Kompetensi dan Kepuasan Kerja Terhadap Kinerja Pegawai pada Badan Perencanaan dan Pembangunan Daerah Kota Lampung. Tesis Universitas Bandar Lampung.

Hamsinah, Herman Sjahruddin, dan Mustafa Gani. 2017. Pengaruh Gaya Kepemimpinan dan Stres kerja terhadap Kepuasan Kerja Karyawan. Jurnal Organisasi dan Manajemen, Issue 2, pp. $62-77$.

Maseda, Arya. 2019. Pengaruh Kepemimpinan dan Lingkungan Kerja Terhadap Kepuasan Kerja Guru dengan Stres Kerja sebagai Variabel Intevening pada Perguruan ArRahman Medan. Universitas Sumatera Utara Medan.

Nugroho, R., Sunuharjo, B. S., \& Ruhana, I. 2017. Pengaruh Iklim Organisasi BPS dan Stres Kerja Terhadap Kinerja Karyawan (Studi pada karyawan Badan Pusat Statistik (BPS) Kabupaten Kediri). Jurnal Administrasi Bisnis, 45(1).

Parayatna, Agus Heri Prayatna dan Made Subudi. 2016. Kepemimpinan Terhadap Stres Kerja dan Kepuasan Kerja Karyawan pada Fave Hotel Seminyak. E-Jurnal Manajemen Unud, Vol. 5, No. 2.

Prayogi, M. A., Koto, M., \& Arif, M. 2019. Kepuasan Kerja sebagai Variabel Intervening Pada Pengaruh Work - Life Balance dan Stres Kerja Terhadap Turnover Intention. Jurnal Ilmiah Manajemen Dan Bisnis, 20 (1), 39 - 51 